\title{
Adaptándose a las circunstancias
}

El presente año ha representado un desafío para todos nosotros. Desde nuestra posición, nos vimos en la imperiosa necesidad de modificar la hoja de ruta preestablecida para este año y adaptarla a las necesidades del momento. Sin embargo, algunos de los principales objetivos que nos habíamos planteado pudimos llevarlos adelante junto con la labor demandada por la emergencia sanitaria.

Separaremos la actividad que hemos realizado este año en dos: gremial y científica.

Desde el punto de vista gremial, nuestra editorial del número anterior ha descrito de forma pormenorizada la participación de la SUC en las distintas situaciones presentadas, que afectaban de forma directa o indirecta la actividad laboral de los cardiólogos.

Sucintamente fueron:

- Amenaza de cierre de la Unidad Cardiológica del CASMU.

- Amenaza de rebaja salarial a cardiólogos de la Asociación Española.

En ambos casos, hemos trabajado en conjunto con la Unidad de Negociación Colectiva del SMU logrando acuerdos positivos, evitando profundizar en la inequidad de atención al paciente y la retribución salarial de nuestros socios. Adicionalmente, la SUC ha apoyado casos individuales que se han visto afectados en su relación laboral debido a la situación de pandemia.

Como parte de la actividad gremial, desde el comienzo de la pandemia en Uruguay ( 13 de marzo de 2020), la directiva ha pasado a funcionar en sesión permanente durante los meses de mayor incertidumbre. Durante este período, hemos asistido a los socios mediante la publicación de las recomendaciones en cuanto a la atención de pacientes. Dichas recomendaciones fueron fruto de una actividad intensa y rápida de cada uno de los comités involucrados. Las mismas fueron sujetas de revisión continua con el objetivo de adaptarse a la situación epidemiológica.

En relación al aspecto científico, describiremos el mismo según la Educación Médica Continua, Congreso anual de cardiología, Comisión de Recertificación y Revista Uruguaya de Cardiología.

La Educación Médica Continua ha logrado adaptarse a la situación emergente y desarrolló dos actividades: COVID y corazón, y Cardio-oncología. Durante el congreso anual se desarrollará la tercera actividad, denominada: Evaluación cardiovascular preparticipativa del deportista en diferentes escenarios clínicos.

El Congreso Uruguayo de Cardiología estaba programado para realizarse en el Centro de Convenciones de Punta del Este. En setiembre de este año, en conjunto con el comité organizador, se decidió modificar dicha modalidad y optar por una opción mixta. Esta opción, es totalmente innovadora en el país y permitirá a la SUC nuevamente ponerse a la vanguardia de la actividad científica. Aprovechando la restricción impuesta por la emergencia sanitaria, se modificó la fecha del congreso presencial para la primera mitad del año. En 2021 la fecha seleccionada es 27 al 29 de mayo y la sede será el Centro de Convenciones de Punta del Este.

A comienzo del año se designó a los Dres. Bernardo Layerle y Washington Vignolo como coordinadores de la recertificación en cardiología por la SUC. Han trabajado de forma activa junto con el Colegio Médico del Uruguay y se ha avanzado en aspectos críticos. La intención es poder tener el reglamento definido en 2021.

Por último, la Revista Uruguaya de Cardiología ha transitado por un cambio histórico en su difusión. Luego de un análisis profundo que involucró aspectos económicos, interés de los socios, y factibilidad de la propuesta, se decidió pasar a un formato $100 \%$ digital. El mismo fue acompañado de una difusión masiva por redes sociales con la intención de llegar a un público más amplio. Nos congratu- 
lamos de la decisión dado que la misma ha sido aceptada de forma muy satisfactoria por nuestros lectores, socios y avisadores que representan un aliado indispensable para lograr este objetivo.

Muchos fueron los objetivos con los que comenzamos el año, algunos pudimos llevarlos a cabo, y a muchos otros no planeados les dimos el encauce necesario. Dirigir la Sociedad Uruguaya de Cardiología implica establecer prioridades contemplando los limitados recursos humanos y económicos. Creemos que cumplimos nuestra función, para la cual los socios nos confiaron la dirección de la sociedad, y dejamos tendidas nuevas líneas de desarrollo para la futura comisión directiva.

\section{Comisión Directiva de la Sociedad Uruguaya de Cardiología}

Este artículo fue aceptado para su publicación por: Editor jefe Dr. Gerardo Soca. 